\title{
INSECTICIDE PROPERTIES OF THE ESSENTIAL OILS FROM HAPLOPAPPUS FOLIOSUS AND BAHIA AMBROSOIDES AGAINST THE HOUSE FLY, MUSCA DOMESTICA L.
}

\author{
ALEJANDRO URZÚA ${ }^{1 *}$, ROCÍO SANTANDER ${ }^{1}$, JAVIER ECHEVERRIA ${ }^{1}$, NANCY CABEZAS ${ }^{1}$, \\ SARA M. PALACIOS ${ }^{2}$ YANINA ROSSI ${ }^{2}$
}

\author{
${ }^{1}$ Laboratory of Chemical Ecology, Faculty of Chemistry and Biology, Universidad de Santiago de Chile, Casilla 40, Correo 33, Santiago, Chile. \\ ${ }^{2}$ Laboratory of Fine Chemicals and Natural Products, Faculty of Chemical Sciences. Catholic University of Córdoba, Camino a Alta Gracia Km 10, (5000) \\ Córdoba, Argentina. \\ (Received: April 27, 2010 - Accepted: July 19, 2010)
}

\begin{abstract}
The compositions of the essential oils (EO's) obtained by hydro distillation from fresh leaves of Haplopappus foliosus and Bahia ambrosoides was analyzed by gas chromatography/mass spectroscopy (GC/MS). The insecticidal activity of each oil against the house fly Musca domestica was evaluated by placing flies in a glass jar with a screw cap that held a piece of EO-treated cotton yarn. The dose necessary to kill $50 \%$ of flies $\left(\mathrm{LC}_{50}\right)$ in $1 \mathrm{~h}$ was determined at $26 \pm 1^{\circ} \mathrm{C}$. The essential oil from Haplopappus foliosus was the most potent insecticide $\left(\mathrm{LC}_{50}=4.43 \mathrm{mg} / \mathrm{dm}^{3}\right)$, wile the EO from Bahia ambrosoides shows only moderated insecticide activity $\left(\mathrm{LC}_{50}=19.27 \mathrm{mg} / \mathrm{dm}^{3}\right)$. According to $\mathrm{GC}$ and $\mathrm{GC} / \mathrm{MS}$ analysis, limonene $(28,00 \%)$; epi-bicyclosesquiphellandrene $(9,84 \%)$; bornyl acetate (7,74\%); 4-terpineol (6,36\%); $p$-cymene (6,00\%); agarospirol (5,53\%); $\alpha$-muurolene $(4,34 \%) ; \delta$-cadinene $(3,98 \%)$ and caryophyllene $(3,97 \%)$ were the principal components of Haplopappus foliosus EO and limonene (28,16\%); $\alpha$-pinene $(11,12 \%)$; germacrene D $(8,81 \%)$; sabinene $(5,93 \%) ; \alpha$-thujene $(3,48 \%) ; \gamma$-curcumene $(3,45 \%)$ y $\alpha$-bergamotene $(3,36 \%)$ were the principal components of Bahia ambrosoides EO.

The EO from Haplopappus foliosus seem promising as a natural insecticide against houseflies and the difference with the activity of the EO of Bahia ambrosoides can be ascribed to the content of oxygenated monoterpenoids and sesquiterpenoids.
\end{abstract}

Keywords: Musca domestica; natural insecticide; essential oils; Haplopappus foliosus; Bahia ambrosoides.

\section{INTRODUCTION}

Musca domestica L. (Diptera: Muscidae) a synanthropic fly, is one of the most common insects associated with man. Flies are mechanical vectors of several human and animal diseases ${ }^{1}$. Recently antibiotic resistant enterococci and staphylococci have been isolated from flies collected near confined poultry operations ${ }^{2}$. In addition, it has been proved that they are potential vectors of metazoan parasites in a pig-pen in Germany ${ }^{3}$.

Many insecticides such as organochlorines, organophosphates, carbamates, pyrethroids and spinosyns, have been used for housefly control ${ }^{4}$. However, insecticide use includes disastrous effects on human health, agro ecosystems, and the environment in general ${ }^{5}$. In addition, houseflies can develop resistance to these pesticides and one of the major mechanisms of resistance is a change in the target site as, for example, acetyl cholinesterase ${ }^{6,7}$.

Integrated pest management programs (IPM) seem to be a good alternative for the control of house flies. These programs combine different control methods that include the use of botanical insecticides ${ }^{1,6}$. Among the botanical insecticides, plant essential oils (or their components) have been evaluated as insecticides because they show a broad spectrum of biological activities that include toxicity, repellency, and oviposition and feeding deterrence ${ }^{8-14}$.

Data on the insecticidal activity of EO's against $M$. domestica are scarce ${ }^{1}$ Matricaria chamomilla and Clerodendron inerme EO's have topical $\mathrm{LC}_{50} \mathrm{~s}$ of 76 and $84 \mu \mathrm{g} / \mathrm{fly}$, respectively ${ }^{15}$. EO's from Citrus sinensis and C. aurantifolia peel showed $72 \pm 7 \%$ and $65 \pm 7 \%$ fumigant effectiveness in killing house flies in a room after $60 \mathrm{~min}$ of spraying, respectively ${ }^{16}$. The insecticidal properties of lemon peel, grapefruit, and navel orange citrus oils against adults and larvae of $M$. domestica have been investigated ${ }^{17}$, and grapefruit peel oil was toxic to $M$. domestica adults while lemon oil was toxic to larvae. Piper betle EO showed a fumigant $\mathrm{LC}_{50}$ of $10.3 \mathrm{mg} / \mathrm{dm}^{3}$ in a 24-h exposure period ${ }^{18}$. Thymus vulgaris $\mathrm{EO}$ showed topical and fumigant activity against larvae and adults of M. domestica in a 24-h period. In comparison with the female and larvae, the male flies were more sensitive to a topical application ${ }^{19}$. Insecticidal properties of EO's of leaves and bark of Cinnamomum zeylanicus, Cymbopogon nardus and Cymbopogon citratus were investigated, the number of fly knock-down after $1 \mathrm{~h}$ was recorded and mortality was assessed $24 \mathrm{~h}$ after topical treatment ${ }^{20}$. The EO of Teucrium leucocladum showed a topical $\mathrm{LC}_{50}$ of $18 \mu \mathrm{g} / \mathrm{larvae}$ in a 24-h period, the sesquiterpene alcohols, patchouli alcohol (31.24\%), $\alpha$-cadinol (9.29\%), $t$-cadinol $(5.48 \%)$, viridiflorol $(5.36 \%)$ and the monoterpene hydrocarbons, $\alpha$-pinene $(10,99 \%)$ and $\beta$-pinene $(12,66 \%)$ were the main components ${ }^{21}$. The insecticidal activity of 34 EO'swere screened against the housefly. The EO of Pogostemon cablin was found to be the most potent topical insecticide, with an $\mathrm{LD}_{50}$ of $3 \mu \mathrm{g} / \mathrm{fly}$ in a 24-h period. The sesquiterpenes: patchouli alcohol $(42.70 \%), \alpha$-selinene $(16.20 \%)$ and $\beta$-patchoulene $(12.30 \%)$ were the main components ${ }^{22}$. The EO of Mentha pulegium was the most potent fumigant insecticide $\left(\mathrm{LC}_{50}=4.7 \mu \mathrm{g} / \mathrm{cm}^{3}\right)$ in a 24-h period. The principal components of the oil were identified as pulegone $(83.30 \%)$ and piperitone $(8.60 \%)^{22}$.

More recently, the insecticide activity of 12 EO's were screened against housefly adults and the dose necessary to kill $50 \%$ of flies $\left(\mathrm{LC}_{50}\right)$ in $30 \mathrm{~min}$ was determined at $26 \pm 1{ }^{\circ} \mathrm{C}$. The EO from Citrus sinensis was the most potent insecticide $\left(\mathrm{LC}_{50}=3.9 \mathrm{mg} / \mathrm{dm}^{3}\right)$, followed by EO'S from C. aurantium $\left(\mathrm{LC}_{50}=\right.$ $4.8 \mathrm{mg} / \mathrm{dm} 3)$ and Eucalyptus cinerea $\left(\operatorname{LC}_{50}=5.5 \mathrm{mg} / \mathrm{dm}^{3}\right)$. Limonene $(92.47 \%)$, linalool $(1.43 \%)$, and $\beta$-myrcene $(0.88 \%)$ were the principal components of C. sinensis EO. Limonene was also the principal constituent (94.07\%) of $C$. aurantium, while 1,8-cineole (56.86\%) was the major constituent of $E$. cinerea $\mathrm{EO}^{23}$.

In continuation of our interest in the potential use of Chilean plants, in the present report we evaluate and compare the insecticide activity of the essential oils of two endemic species of widespread occurrence in the coastal region of the V Region, Haploppapus foliosus and Bahia ambrosoides ${ }^{24}$, in what is the first study on the use as natural insecticides against Musca domestica of EO's from the Chilean flora. Besides their monospecific occurrence as dominant species in large areas ${ }^{24}$, the choice of these species was motivated by field observations of their apparent resistance to insect aggression. As far as we are concerned, the composition of essential oils from Bahia species has never been investigated, and there is only one report on EO's from Haploppapus greenei, with an interesting antifungal activity 25 .

\section{RESULTS AND DISCUSSION}

From the fresh leaves of B. ambrosoides and H. foliosus, $1.4 \mathrm{~g}$ and $1.2 \mathrm{~g}$ of EO's were obtained, respectively. The composition of the EO's (\%) are listed in Table 1. Limonene $(28.00 \%)(\mathbf{1})$; epi-bicyclosesquiphellandrene $(9.84 \%)$ (2); bornyl acetate $(7.74 \%)(3)$; 4-terpineol $(6.36 \%)(4)$; $p$-cymene $(6.00 \%)$ (5); agarospirol $(5.53 \%)(6) ; \alpha$-muurolene $(4.34 \%)(7) ; \delta$-cadinene $(3.98 \%)(8)$ and caryophyllene $(3.97 \%)(9)$ were the principal components of Haplopappus foliosus EO and limonene $(28.16 \%)(\mathbf{1}) ; \alpha$-pinene $(11.12 \%)(\mathbf{1 0})$; germacrene D $(8.81 \%)(\mathbf{1 1})$; sabinene $(5.93 \%)(\mathbf{1 2}) ; \alpha$-thujene $(3.48 \%)(\mathbf{1 3}) ; \gamma$-curcumene $(3.45 \%)(\mathbf{1 4})$ and $\alpha$-bergamotene $(3.36 \%)(\mathbf{1 5})$ were the principal components of B.ambrosoides EO. 
Table 1 Percentage composition of the essentials oils of leaves of Bahia ambrosoides and Haplopappus foliosus.

\begin{tabular}{|c|c|c|c|c|}
\hline Compound & R.I & $\mathrm{B}(\%)$ & $\mathbf{H}(\%)$ & Identification \\
\hline (E)-2-Hexenal & 850 & 0.31 & 0.13 & RI, MS \\
\hline$\alpha$-Thujene (13) & 924 & 3.48 & 1.23 & RI, MS \\
\hline$\alpha$-Pinene (10) & 931 & 11.12 & 0.89 & RI, MS, Co-I \\
\hline Camphene & 945 & 0.34 & 0.16 & RI, MS \\
\hline Sabinene (12) & 971 & 5.93 & 0.93 & RI, MS \\
\hline$\beta$-Pinene & 974 & & 1.43 & RI, MS, Co-I \\
\hline$\beta$-Myrcene & 988 & 2.03 & 2.76 & RI, MS \\
\hline$\alpha$-Phellandrene & 1001 & 1.23 & 0.22 & RI, MS \\
\hline 3-Carene & 1014 & 0.16 & & RI, MS \\
\hline$\alpha$-Terpinene & 1014 & & 0.90 & RI, MS \\
\hline$p$-Cymene (5) & 1023 & & 6.00 & RI, MS, Co-I \\
\hline Limonene (1) & 1030 & 28.16 & 28.00 & RI, MS, Co-I \\
\hline (E)-Ocimene & 1045 & 1.84 & & RI, MS, Co-I \\
\hline$\gamma$-Terpinene & 1056 & 0.33 & 2.02 & RI, MS \\
\hline Isoterpinolene & 1065 & & 0.26 & RI, MS \\
\hline Terpinolene & 1085 & 0.35 & & RI, MS \\
\hline cis-Rose oxide & 1106 & 0.33 & & RI, MS \\
\hline trans-Pinocarveol & 1138 & 0.47 & & RI, MS \\
\hline Borneol & 1166 & 0.45 & 0.32 & RI, MS, Co-I \\
\hline 4-Terpineol (4) & 1176 & 1.04 & 6.36 & RI, MS, Co-I \\
\hline$\alpha$-Terpineol & 1185 & & 0.09 & RI, MS, Co-I \\
\hline Myrtenol & 1196 & 2.21 & & RI, MS \\
\hline Citronellol & 1223 & 0.51 & & RI, MS \\
\hline Bornyl acetate (3) & 1284 & 1.29 & 7.47 & RI, MS, Co-I \\
\hline trans-Pinocarvyl acetate & 1297 & 1.00 & & RI, MS \\
\hline Myrtenyl acetate & 1324 & 2.38 & & RI, MS \\
\hline 1,5,5-Trimethyl-6-metylenecyclohexane & 1338 & 0.70 & & RI, MS \\
\hline Citronellyl acetate & 1345 & 1.01 & & RI, MS \\
\hline$\alpha$-Cubebene & 1351 & 0.12 & 0.92 & RI, MS \\
\hline$\alpha$-Copaene & 1379 & 1.04 & & RI, MS \\
\hline$\beta$-Cubebene & 1392 & 0.57 & 1.66 & RI, MS \\
\hline$\alpha$-Bergamotene (15) & 1436 & 3.36 & & RI, MS \\
\hline Caryophyllene (9) & 1440 & & 3.97 & RI, MS \\
\hline Alloaromadendrene & 1459 & 0.89 & & RI, MS \\
\hline epi-Bicyclosesquiphellandrene (2) & 1467 & 0.50 & 9.84 & RI, MS \\
\hline$\gamma$-Curcumene (14) & 1482 & 3.45 & & RI, MS \\
\hline$\gamma$-Muurolene & 1485 & & 1.03 & RI, MS \\
\hline Germacrene-D (11) & 1489 & 8.81 & 1.30 & RI, MS \\
\hline$\alpha$-Zingiberene & 1493 & 2.33 & & RI, MS \\
\hline$\delta$-Amorphene & 1499 & 0.89 & & RI, MS \\
\hline$\alpha$ - Muurolene (7) & 1500 & & 4.34 & RI, MS \\
\hline$\gamma$-Cadinene & 1520 & & 1.36 & RI, MS \\
\hline$\delta$-Cadinene (8) & 1525 & 2.37 & 3.98 & RI, MS \\
\hline Spathulenol & 1576 & & 0.70 & RI, MS \\
\hline Agarospirol (6) & 1636 & & 5.53 & RI, MS \\
\hline$\zeta$-Muurolol & 1646 & 0.57 & & RI, MS \\
\hline$\alpha$-Bisabolol & 1652 & & 0.82 & RI, MS \\
\hline
\end{tabular}

B: Bahia ambrosoides; H: Haplopappus foliosus; RI: Retention index; MS: Mass spectrum; Co-I: standard. 
<smiles>C=C(C)C1CC=C(C)CC1</smiles><smiles>C=C1C=C2C(C(C)C)CCC(C)C2CC1</smiles><smiles>CC(=O)OC1CC2CCC(C1)C2(C)C</smiles><smiles>CC1=CCC(O)(C(C)C)CC1</smiles><smiles>Cc1ccc(C(C)C)cc1</smiles><smiles>CC1=CCCC2CC(C(C)(C)O)CCC12</smiles><smiles>CC1=CCC2C(C(C)C)CCC3CC(C)=C[C@@]32CC1</smiles><smiles>CC1=CC2C(=C(C)CCC2C(C)C)CC1</smiles><smiles>C=C1CCC=C(C)CCC2C1CC2(C)C</smiles><smiles>CC1=CCC2CC1C2(C)C</smiles><smiles>CC1=CCCC(C)(C)CCC1C(C)C</smiles><smiles>C=C1CCC2(C(C)C)CC1C2</smiles>

12<smiles></smiles>

13<smiles>CC(C)=CCCC(C)C1=CC=C(C)CC1</smiles>

14

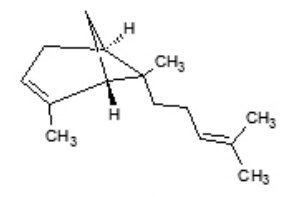

15

Figure 1: Principal terpenoids in the essential oils of Haplopappus foliosus and Bahia ambrosoides.

Both EO'S contain similar monoterpenic hydrocarbon compositions, with the same percentage of limonene but with significant differences in content and composition of the oxygenated monoterpenes and sesquiterpene fractions. The Jaccard similarity coefficients ${ }^{26}$ for the different groups of terpenoids are shown in table 2. It is seen that, whereas the monoterpenic hydrocarbons exhibit a high similarity coefficient $(0.5)$, this value is significantly smaller for the oxygenated monoterpenes and sesquiterpenes fractions, falling to 0.15 and 0.25 respectively.

Table 2: Jaccard coefficient for comparisons involving compositions of different families of terpenoids found in the essential oils of Bahia ambrosoides and Haplopappus foliosus.

\begin{tabular}{lccc}
\hline Comparison & $\underline{\mathrm{HM}}$ & $\underline{\mathrm{OM}}$ & $\underline{\mathrm{SQ}}$ \\
\hline J.coefficient & J.coefficient & J.coefficient \\
\hline B. ambrosoides - H.foliosus & 0.5 & 0.15 & 0.25 \\
\hline
\end{tabular}

HM: hydrocarbon monoterpenes; OM: oxygenated monoterpenes; SQ: sesquiterpenes

The fumigant effects of EO'S against adult $M$. domestica were evaluated by determining the $\mathrm{LC}_{50}$ values, which are presented in Table 3 .

Table 3: $\mathrm{LC}_{50}$ of essential oils against Musca domestica.

\section{Essential oil}

\section{Haplopappus foliosus}

Mean $\mathrm{LC}_{50}$ in $\mathrm{mg} / \mathrm{dm}^{3}(95 \% \mathrm{CI})$

\section{Bahia ambrosoides}

$19.27(7.15-51.96)$

Time : $1 \mathrm{~h} ; \mathrm{t}: 26 \pm 1^{\circ} \mathrm{C}$

The most effective insecticide was the EO derived from $H$. foliosus with $\mathrm{LC}_{50}$ value of $4.43 \mathrm{mg} / \mathrm{dm}^{3}$ of air, while the EO from B. ambrosoides showed only moderate insecticide activity $\left(\mathrm{LC}_{50}=19.27 \mathrm{mg} / \mathrm{dm}^{3}\right)$.

The EO from B. ambrosoides contains $39.28 \%$ of limonene and $\alpha$-pinene. The insecticide properties of both compounds have been determined using the same bioassay, and the $\mathrm{LC}_{50}$ in a $0.5 \mathrm{~h}$ experiment were $12.1 \mathrm{mg} / \mathrm{dm}^{3}$ for $\alpha$-pinene, $6.2 \mathrm{mg} / \mathrm{dm}^{3}$ for $(4 R)(+)$-limonene and $5.0 \mathrm{mg} / \mathrm{dm}^{3}$ for $(4 S)$ (-)-limonene ${ }^{23}$. The insecticide activity of the essential oils may be related in principle with the composition and the insecticide activity of the individual components. However, the possibility of synergistic/antagonistic effects cannot be ruled out. For example the insecticide activity of the essential oil of Mentha pulegium, that contains more than $75 \%$ of pulegone, was found to be 9 times less effective against Drosophila melanogaster than pure pulegone ${ }^{27}$. This example is an indication that direct correlations between the concentration of an active compound in its pure form and in various plant extracts should be made with some caution. Nevertheless, the presence of limonene and $\alpha$-pinene in the $\mathrm{EO}$ of $B$. ambrosoides might explain its rather moderate activity. By contrast, the greater insecticide activity of the EO of $\mathrm{H}$. foliosus cannot be explained solely by the presence of limonene $(28.00 \%)(\mathbf{1})$. The EO of $H$. foliosus contains 4-terpineol $(6.36 \%)$ (4) the principal component of the essential oil of Myristica fragrans, with a reported insecticide activity against M. domestica ${ }^{23}$. It also contains $35.45 \%$ of sesquiterpenoids, among them caryophyllene (9), $\alpha$-muurolene (7) and agarospirol (6), compounds not found in the $\mathrm{EO}$ of $B$. ambrosoides. A second noteworthy difference in composition is the high content of epi-bicyclosesquiphellandrene (ca.10\%) (2) found in $H$. foliosus and completely absent in B. ambrosoides. The greater insecticide activity of the essential oil of $H$. foliosus might be due to the high content of sesquiterpenes and oxygenated monoterpenes. Sesquiterpenes are the main components of the essential oils of Teucrium leucocladum and Pogostemon cablin, both potent topical insecticides against $M$. domestica ${ }^{21,22}$.

\section{EXPERIMENTAL}

\subsection{General}

1,8-Cineole; limonene; $\alpha$-pinene; $\beta$-pinene; $\alpha$-terpinene; $\gamma$-terpinene and terpineol were purchased from Sigma-Aldrich (St. Louis, MO, USA). Dimethyl2,2-dichlorovinyl phosphate (DDVP) was a gift of Professor H. Masuh, from the Center of Investigation on Pests and Insecticides, CONICET, Argentina. The essential-oil component analysis was performed by gas chromatography and gas chromatography/ mass spectroscopy (GC/MS). Qualitative analyses were performed in a Hewlett-Packard 5891 gas chromatograph linked to a Hewlett-Packard 5972 mass spectrometric detector with an integrated data system (Hewlett Packard, Palo Alto, CA, USA); quantitative analyses were carried out with a Shimadzu GC-9A gas chromatograph fitted with a FID-9 detector (Shimadzu Corporation, Kyoto, Japan). The same capillary column (SPB-5, film thickness $0.25 \mu \mathrm{m}, 30 \mathrm{~m}$ x $0.25 \mathrm{~mm}$, Supelco, Deerfield IL, USA) was used in both instruments.

\subsection{Plant material}

Leaves of $H$. foliosus D.C. (Asteraceae, Asterales) and B. ambrosoides Lag. (Asteraceae, Asterales), were collected in November 2008, in Los Molles (V Region, Chile $32^{\circ} 30^{\prime} \mathrm{S}, 71^{\circ} 30^{\prime} \mathrm{W} 32^{\circ}$ ). Voucher specimens were deposited in the Herbarium of the National Natural History Museum, Santiago, Chile

\subsection{Essential oil extraction and analysis}

Essential oils were extracted from $500 \mathrm{~g}$ of fresh leaves for $2 \mathrm{~h}$ by hydro distillation in a Clevenger-type apparatus. The EO's were dried over anhydrous sodium sulfate. The EO component analysis was performed by gas chromatography and gas chromatography/mass spectroscopy (GC/MS) using the instrumentation described above. The operating conditions were as follows: on-column injection; injector temperature, $250^{\circ} \mathrm{C}$; detector temperature, $280^{\circ} \mathrm{C}$; carrier gas, $\mathrm{He}$ at $1.25 \mathrm{ml} / \mathrm{min}$; oven temperature program: $35{ }^{\circ} \mathrm{C}$ for $5 \mathrm{~min}$, increase to $260{ }^{\circ} \mathrm{C}$ at $5{ }^{\circ} \mathrm{C} / \mathrm{min}$, and then $260^{\circ} \mathrm{C}$ for $5 \mathrm{~min}$. The mass detector ionization employed an electron impact of $70 \mathrm{eV}$. Recording conditions employed a scan time of $1.5 \mathrm{~s}$ and a mass range of 50 to $500 \mathrm{amu}$. Compounds in the chromatograms were identified by comparison of their mass spectra with those in the NIST98 library database, and by comparison of their retention index with those reported in the literature for the same type of column or those of commercial standards, when available ${ }^{28}$.

\subsection{Fly collection and maintenance}

Colonies of $M$. domestica originated from adults were collected from the experimental field of the Universidad Católica of Córdoba, in Córdoba, Argentina, using a sweep net. The flies were transferred to a small cage and then reared in entomological cages $(30 \times 30 \times 30 \mathrm{~cm})$ at $26( \pm 1){ }^{\circ} \mathrm{C}$ under a 12:12 light: dark cycle and $70 \%$ humidity. Adult flies were provided with water and fed a 1:1 (v/v; approximately) mixture of granulated sugar and powdered milk. Bran and milk were prepared at a weight ratio of $1: 3$ and $100 \mathrm{~g}$ of this mixture was placed on a plastic plate as an oviposition site. 


\subsection{Bioassay}

The bioassay was designed such that the flies would have high probability of coming into contact with the volatile compounds within the one hour test period; therefore, the flies were allowed access to the total space within the exposure vessel. Ten 4-5 day-old adult house flies, of both sexes, were placed in a glass jar $\left(1.2 \mathrm{dm}^{3}\right)$ fitted with a screw cap with a $7-\mathrm{cm}$ length of cotton yarn suspended from the center of the internal face of the cap. Different dosages of pure EO (without solvent) were applied to the yarn. The control vessel had no compound on the cotton yarn. The jars were then sealed tightly. The jars were maintained in a room at $26 \pm 1{ }^{\circ} \mathrm{C}$. Each test was replicated three times. The assay was also run with the cotton yarn enclosed in a bag made of breathable cloth so that the flies could not contact the yarn. Dimethyl 2, 2-dichlorovinyl phosphate (DDVP), a volatile organophosphate, was used as a positive control. Mortality in each group was assessed after a one our exposure.

\subsection{Data analysis}

Similarity in the composition of the different type of terpenoids between the EOs of B. ambrosoides and H.foliosus (hydrocarbon monoterpenes, oxygenated monoterpenes and sesquiterpenes) was compared with the Jaccard similarity coefficient, which uses presence-absence data. Comparisons between different taxa should give values between 0 and $1^{26}$.

The mean mortality data of the three replicates per doses (4-6 doses per EO) was used to calculate the $\mathrm{LC}_{50}$. Probit analysis (Harvard Programming; $\mathrm{Hg} 1,2)$ was used to analyze the dose-mortality response.

\section{ACKNOWLEDGEMENTS}

Financial support for this work was provided by Universidad de Santiago de Chile, DICYT, 020941 UM and FONCYT, PICT 33593 (Argentina)

\section{REFERENCES}

1. A. Malik, N. Singh, S. Satya, J. Environ. Sci. Health. B. 42, 453, (2007)

2. JP. Graham, LB. Price, SL. Evans, TK. Graczyk, EK. Silberged, Sci. of the Total Environ. 407, 2701, (2009)

3. M. Förster, S. Klimpel, K. Sievert, Veterinary Parasitology, 160, 163, (2009)

4. GJ. Devine, MJ. Furlong, Agricultural and Human Values, 24, 281, (2007)

5. F. Bakkali, S. Averbeck, D. Averbeck, M. Idaomar, Food and Chemical Toxicology, 46, 446 (2008)
6. RK. Tripathi, RD. O'Brien, Pestic. Biochem. Physiol., 3, 495 (1973)

7. T. Kozaki, SG. Brady, JG. Scott, Pestic. Biochem. Physiol., in press, doi: 10.1016/j.pestbp.2009.04.015

8. G. Rosell, C. Quero, J. Coll, A. Guerrero, J. Pestic. Sci., 33, 103 (2008)

9. DR. Batish, HP. Singh, RK Kohli, S. Kaur, Forest Ecology and Management, 256, 2166 (2008)

10. MA. Ibraim, P. Kainulainen, A. Aflatuni, JK. Holopainen, Agric. Frood Chem. In Finland, 10, 243 (2001)

11. Regnault-Roger, C. Integr. Pest Manag. Rev., 2, 25 (1997)

12. MB. Isman, Crop Protect. 2000, 19, 603, (2000)

13. MB. Isman, CM. Machial, Pesticides based on plant essential oils: from traditional practice to commercialization. In Advances in Phytomedicine; Rai M., Carpinella M.C., Eds.; Elsevier: Amsterdam, The Netherlands, 2006, pp. 29-44.

14. Coats, J.R.; Karr, L.L.; Drewes, C.D. Toxicity and neurotoxic effects of monoterpenoids in insects and earthworms. In Naturally Occuring Pest Bioregulators. ACS Symposium Series 449, Hedin P.A., Ed.; ACS: Washington, DC, U.S.A., 1991, pp. 306-316.

15. Shoukry, I.F. J. Egypt. Soc. Parasitol., 27, 893 (1997)

16. Ezeonu, F.C.; Chidume, G.I.; Udedi, S.C. Biores. Technol., 76, 273 (2001)

17. Shalaby, A.A.; Allam, K.A.; Mostafa, A.A.; Fahmy, S.M. J. Egypt. Soc. Parasitol., 28, 595 (1998)

18. Mohottalage, S.; Tabacchi, R.; Guerin, P.M. Flavour Frag. J., 22, 130 (2007)

19. R. Pavela, J. Essent. Oil Bearing plants, 10, 346 (2007)

20. R. Samarasekera, KS Kalhari, J. Essent. Oil Res., 18, 352 (2006)

21. AM. El-Shazly, KT.Hussein, Biochem. Syst. Ecol., 32, 665 (2004)

22. R. Pavela, Phytotherapy Res., 22, 274 (2008)

23. SM. Palacios, A. Bertoni, Y. Rossi, R. Santander, A. Urzúa, Molecules, 14, $1938(2009)$

24. P. Riedeman, G. Aldunate, "Flora nativa de valor ornamental Identificación y Propagación, Chile Zona Centro", Editorial Andrés Bello, Chile, (2001)

25. B. Demirci, K Husnu, C. Baser, N. Tabanca, D E. Wedge, J. Agric. Food Chem.,54,3146 (2006)

26. CJ. Krebs, "Ecological methodology", Harper and Row, New York, (1989)

27. G. Franzios, M. Mirotsou, E. Hatziapostolou, J. Karl, ZG. Scouras, P. Mavragani-Tsipidou, J. Agric. Food Chem., 45, 2690 (1997)

28. A.Urzúa, G. Sotes, J. Chil. Chem. Soc., 53, 1361 (2008). 